Int. J. Dev. Biol. 53: 1421-1426 (2009)

doi: $10.1387 / \mathrm{ijdb} .072285 \mathrm{sp}$

\title{
Portuguese contributions to the discovery and characterization of the embryonic molecular clock
}

\author{
SUSANA PASCOAL\# and ISABEL PALMEIRIM* \\ Life and Health Sciences Research Institute (ICVS), School of Health Sciences, University of Minho, Braga, Portugal
}

\begin{abstract}
Embryonic development is strictly regulated both in time and in space. This extraordinary control is clearly evidenced during the process of somitogenesis. In this process, pairs of somites are formed periodically, such that the time required to form a new somite pair is constant and species specific. The tight temporal control underlying somitogenesis has been shown to depend upon a molecular clock, manifested by the cyclic expression of an increasing number of genes in the unsegmented paraxial mesoderm. Portuguese researchers have been intimately connected to the achievements that have been made in this new field of research: the somitogenesis molecular clock. This article intends to report the Portuguese contributions to the discovery and characterization of the molecular clock underlying somite formation and possibly other embryonic processes. This work inspired many scientists around the world and it has been followed in Portugal by teams that keep on pursuing the characterization of the machinery of this molecular oscillator and its function in the acquisition of both temporal and positional information during development.
\end{abstract}

KEY WORDS: somitogenesis, temporal control, limb bud, positional information, L-R asymmetry

\section{Introduction}

Vertebrae are emblematic structures of vertebrate organisms and are laid-down during the very first steps of embryogenesis. During early vertebrate embryo development, axial structures (notochord and neural tube) are flanked bilaterally by the unsegmented paraxial mesoderm or presomitic mesoderm (PSM). This mesodermal tissue is progressively subdivided in an anterior to posterior direction into pairs of epithelial spheres of cells, the somites. Concomitantly, gastrulation proceeds in the posterior part of the embryo generating new mesodermal cells that incorporate PSM and in this way guarantee embryo elongation (Fig. 1). Somites are transient embryonic structures that later on give rise to the trunk bone elements (vertebrae, intervertebral disks and ribs), to all the skeletal muscles of the body, except those of the head, to the dermis of the back and to muscle limb tendons (Rida et al., 2004).

Somite pairs are generated with a clock-like precision involving tight spatial and temporal regulation, i.e., the time required to form a pair of somites, as well as the final somite number, is constant and characteristic for each species (for example, in the chick embryo a new pair of somites is formed every 90 minutes, culminating in a total of 52 somite pairs). This fact suggests the existence of an internal clock-like machinery controlling both the rhythm and duration of somitogenesis, in a species-specific manner (reviewed by Freitas et al., 2005; Andrade et al., 2005, 2007). In fact, the existence of such a cellular clock had been suggested about 30 years ago by Cooke and Zeeman in a theoretical model named "The clock and wavefront model" (Cooke and Zeeman, 1976).

The first steps of the discovery of the somitogenesis clock

In 1997, Isabel Palmeirim, a Portuguese researcher working at Nicole Le Douarin's laboratory (Institut d'Embryologie Cellularie et Moleculaire de Nogent-sur-Marne, France) under Olivier Pourquié's supervision, performed several experiments to study the expression pattern of two chick homologues of the Drosophila hairy segmentation gene, hairy1 and hairy2, during the process of somitogenesis. These genes had been previously cloned by Domingos Henrique, another Portuguese researcher working at David Ish-Horovicz's laboratory (Imperial Cancer Research Fund,

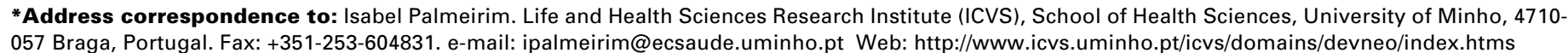

\# New address: Instituto Gulbenkian de Ciência, Centro de Biologia do Desenvolvimento, Rua da Quinta Grande 6, 2780-156 Oeiras, Portugal.

Final author-corrected PDF published online: 7th May 2008.

ISSN: Online 1696-3547, Print 0214-6282

(c) 2008 UBC Press

Printed in Spain 
UK), since the Drosophila hairy gene plays an important role in neurogenesis, the main interest of this research group at the time.

By performing whole-mount in situ hybridization experiments, Isabel observed that chick embryos with the same somite number presented a huge variety of both hairy 1 and hairy 2 expression patterns in the unsegmented paraxial mesoderm. This initial observation suggested that hairy1 and hairy2were expressed in a very dynamic manner in the PSM (Fig. 2). To further characterize this dynamic behavior, a tridimensional in vitroculture system for chick explants was established and used to culture half-chick embryos generated by cutting the neural tube down the midline. In the first experiment, one embryo half was immediately fixed, while the other was incubated for short time periods. The evaluation of the expression patterns on both control and experimental PSMs clearly showed that hairy1 and hairy2 expression varied within the PSM cells, being 30 minutes of incubation sufficient to completely change the expression patterns of these genes. On the contrary, the same expression pattern was obtained when the experimental half was incubated for 90 minutes (Fig. 3A). From these results the authors concluded that hairy1 and hairy2was cyclically expressed in the PSM cells with a periodicity of 90 minutes, time that corresponds to the formation of one pair of somites (Palmeirim et al., 1997). Additional experiments, illustrated in Fig. 3 B,C, also demonstrated that hairy1 and hairy2cyclic expression is an intrinsic property of the PSM cells, independent from any surrounding tissue or signal arising from the gastrulation site (Palmeirim et al., 1997). In a first analysis, hairy1 and hairy2 expression pattern appears like a posterior to anterior wave along the PSM. However, this wave of hairy1 and hairy2 expression only corresponds to a "kinematic" wave, i.e., a wave that progresses independently from communication between neighboring cells, suggesting that these PSM cell oscillations result from an intrinsic program of each PSM cell. The wave-like pattern arises from the fact that neighboring cells are slightly out-of-phase with respect to their autonomous oscillations.

All the evidences obtained until now indicate that each PSM cell undergoes many cycles of hairy1expression until it is incorporated into a somite. In this way a PSM cell could register the number of gene expression cycles it has undergone, and then this information could be translated into positional information along the anteriorposterior PSM axis, at any given time.

\section{Running after the clock, around the clock...}

Since the discovery of the molecular clock in 1997, various research groups devoted their investigation to this subject. Until

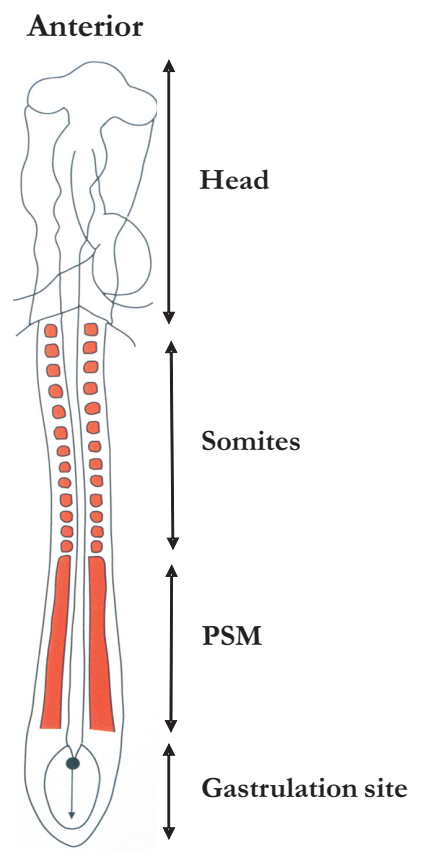

Posterior
A

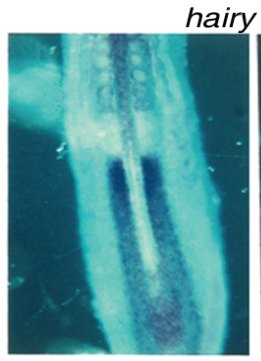
hairy 1 expression pattern
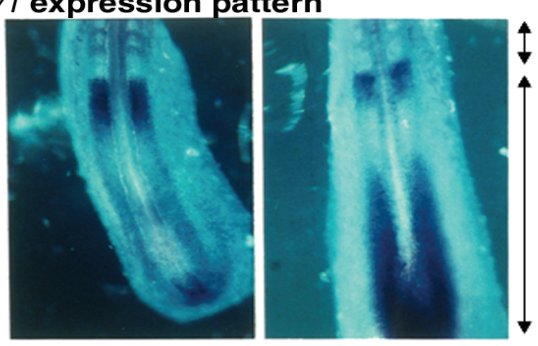

I Newly formed somites

PSM

B

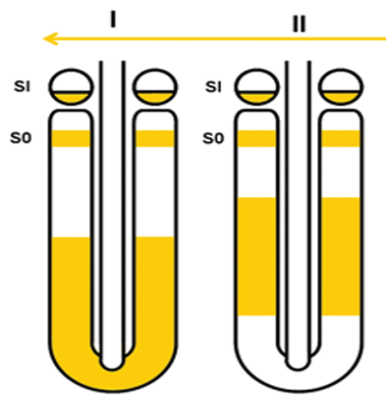

III

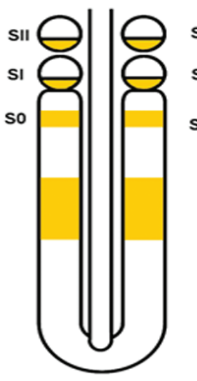

1

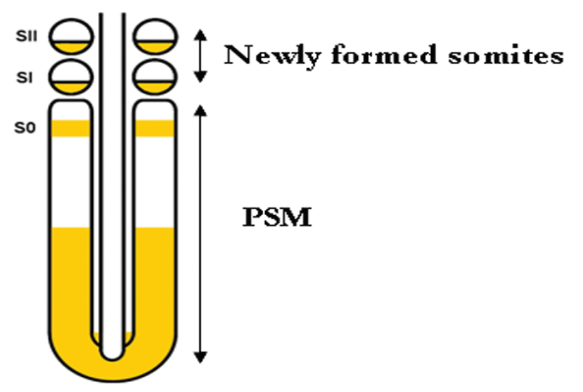

Fig. 1 (Left). Schematic representation of a dorsal view of a chick embryo with $\mathbf{4 8}$ hours of incubation. At this developmental stage, the paraxial mesoderm (represented in red) can be subdivided into an anterior compartment where paraxial mesoderm is segmented into epithelial balls of cells, the somites, and a posterior compartment that corresponds to the unsegmented paraxial mesoderm or presomitic mesoderm (PSM). Posteriorly, the process of gastrulation is still occurring producing more mesodermal cells that penetrate the caudal part of the PSM and assure its posterior elongation. The head of the embryo is to the top.

Fig. 2 (Right). Chick hairy1 and hairy2 genes present a variable expression pattern in the presomitic mesoderm. (A) Dorsal view of the caudal part of chick embryos after two days of incubation that were hybridized with the hairy1 probe; a high variability of expression patterns can be observed in these embryos at the level of the presomitic mesoderm (PSM). (B) Schematic representation of the expression cycle of a molecular clock gene; while one somite is being formed in the most rostral part of the PSM, a kinematic "wave" of hairy1 and hairy2 expression travels across the PSM anterior-posterior axis. This cyclic expression pattern is reiterated every 90 minutes. In newly formed somites, hairy 1 and hairy2 are expressed in their posterior and anterior compartment, respectively. 
now, many genes were found to present a cyclic behaviour in the PSM of several animal model embryos (mouse, chick, zebrafish, frog and medaka), showing that the molecular mechanisms underlying somitogenesis are conserved among vertebrates. The majority of the cyclic genes found code for Hairy/Enhancer-of-Split (Hes) family targets of the Notch signalling pathway. Other cycling genes encode a modulator of the Notch signalling pathway, lunatic fringein the chick and mouse and a Notch ligand, deltaC, in zebrafish (reviewed by Freitas et al., 2005 and Andrade et al., 2005). Recently, the Wnt signalling pathway was also implicated in the segmentation clock with the discovery of new cyclic genes belonging to this pathway. Axin2, a repressor of the Wnt signalling pathway, nkd1, a Wnt antagonist, and dact1, a gene that encodes conserved Dishevelled (Dvl)binding regulators of WNT signalling pathway, were shown also to exhibit an oscillatory expression in the mouse PSM, suggesting a reciprocal interaction of Notch and Wnt signals in the regulation of the segmentation clock (Aulehla et al., 2003, Ishikawa et al., 2004, Suriben et al., 2006, Fisher et al., 2006). Furthermore, it has been demonstrated that snail1 and snail2 genes are cyclically expressed in the mouse and chick presomitic mesoderm, respectively. Surprisingly, these snail gene oscillations are independent of Notch signalling (Dale et al., 2006). Finally, very recent microarray studies of the mouse PSM transcriptome revealed that the periodic expression of a large network of genes involved in cell signaling. Many of the cyclic genes identified belong to the Notch, Wnt and FGF pathways, suggesting that the oscillator mechanism largely relies on these three pathways (Dequéant et al., 2006).

A negative feedback regulation has been identified for the hes 1 and hes7genes in mouse. Studies at the protein level confirmed that these gene products present oscillations with the same periodicity found for their counterpart mRNAs. Moreover, they inhibited their own promoters creating negative feedback loops (reviewed in Rida et al., 2004 and Freitas et al., 2005). An additional negative feedback regulation has been described for lunatic fringe gene in chick (Dale et al., 2003). The Lunatic fringe protein oscillates in PSM cells, periodically inhibiting Notch signalling, and consequently down-regulating /unatic fringe expression. These negative feedback loops may represent important elements in the segmentation clock mechanism. Using mathematical modelling, Monk showed that oscillatory gene expression could result essentially from transcriptional delays, and that the oscillation period could be determined by the delay in transcription and by both protein and mRNA half-lives (Monk, 2003). In agreement, Hes7 protein instability was recently shown to be vital for the segmentation clock (Hirata et al., 2004).

\section{The clock is ticking in two dimensions}

Meanwhile, Isabel Palmeirim returned to Portugal and established her own laboratory at the Instituto Gulbenkian de
Ciência (IGC), Oeiras. Work largely performed by her Portuguese Ph.D. students Catarina Freitas and Sofia Rodrigues provided data supporting that the molecular clock is already operating in PSM prospective cells and that this clock could be providing cell positional information on both antero-posterior (AP) and medio-lateral (ML) axes (Freitas etal., 2001). Detailed fate map studies performed by Catarina Freitas and MarieAimée Teillet (Institut d'embryologie, Nogent-sur-Marne, France) allowed the completion of a previous fatemap (Catala et al., 1996) showing that different regions of the prospective PSM territory give rise to distinct PSM compartments: cells located anteriorly, near to the Hensen's node, give rise to medial PSM cells, while more posterior cells develop into lateral PSM domain (Freitas et al., 2001). A detailed whole-mount and cross-section analysis of the expression patterns of cycling genes (hairy1, hairy2 and lunatic fringe) performed by Sofia Rodrigues revealed that the segmentation clock is already operating in the prospective PSM territory and a wave of expression can be observed between ML prospective PSM cells (Freitas et al., 2001). In agreement, an asynchrony in cyclic gene expression can also be observed between the medial and lateral portions of the PSM, which is evidenced by the appearance of cross-stripes in this tissue. These studies suggest that the molecular clock associated with vertebrate segmentation is providing cellular positional information in at 
least two dimensions: AP and ML (Freitas et al., 2001).

The molecular clock needs to be synchronized between the left and the right side of the embryo

The vertebrate adult body presents a symmetric organization at the level of the axial skeleton, while most of the internal organs are asymmetrically distributed within abdominal and thoracic cavities. It has been generally believed that vertebrate embryos are symmetric by default, i.e., no information is needed in order to maintain the original symmetry of the early vertebrate embryo. In the last decade, signals responsible for the establishment of vertebrate body asymmetry have been progressively uncovered. We now know that normal asymmetric organ distribution is the result of asymmetric gene expression at the level of the lateral plate mesoderm (Fig. 4A). In contrast, axial symmetry can be achieved by the bilateral synchrony of the clock cyclic gene expression involved in the somitogenesis process (Fig. 4A). Leonor Saúde, a Portuguese post-doc researcher working at the IGC, in Palmeirim's group, identified Terra as an essential gene to ensure bilaterally symmetric expression of the molecular clock genes that underlie vertebrae formation. Furthermore, this gene was proved to be the first molecular link between two major events: Left-Right (L-R) asymmetrical patterning and bilateral synchronization of the segmentation clock. In agreement, the absence of Terra results in both a randomization of lateral plate mesoderm markers and a bilateral desynchronization of the segmentation clock (Fig. 4B). These results are consistent with a model in which Terra acts early in development to promote L-R information flow and protect the PSM from the asymmetrical signals, ensuring symmetry in all structures derived from this tissue (Saúde et al., 2005).

\section{The molecular clock operates during limb bud devel- opment}

Until very recently all cyclic genes described in vertebrate embryos were expressed exclusively in the PSM cells. But could the clock be working in other developmental processes? The first advance in this direction was the work performed by Hirata and co-workers (2002), which described that administration of a single serum shock to several cell lines, such as myoblasts, fibroblasts, neuroblastoma cells and teratocarcinoma cells, could induce cyclic production of both hes $1 \mathrm{mRNA}$ and protein. The observed oscillations occurred with a 2 hours time period, corresponding to the periodicity of cyclic gene expression observed in the mouse embryo PSM. These results led the authors to suggest that the molecular clock may regulate the timing in many biological systems (Hirata et al., 2002).

Limb bud development requires a precise orchestration of cell proliferation and differentiation in time and space. The limb is a segmented structure and its skeletal elements (stylopode, zeugopode and autopod) are laid down as cartilaginous primordia that grow in a proximal-distal $(p-d)$ sequence. Two models have been put forward to explain cell fate specification along the $p-d$ limb axis: the progress zone model (Summerbell et al., 1973) and the early specification model (Dudley et al., 2002). According to the first model, cells located in the most distal part of the limb bud mesenchyme (the progress zone-PZ) convert the time spent in this region into positional information: cells leaving the PZ early give rise to humerus and those leaving last form digits (Summerbell et al., 1973). The early specification model proposes that cell populations giving rise to different $p-d$ limb structures are specified earlier in development (Dudley et al., 2002). Afterwards, previously specified limb cell populations expand one after another, such that cells of proximal structures start proliferating first and cells of distal structures last. Thus, both models imply the existence of a limb bud distal zone where cells reside until they reach the time to differentiate (progress zone model) or to expand (early specification model). However, nothing is known about how these cells measure time.

The first evidence that the molecular clock is working in other embryonic proliferating tissues was made by another Portuguese Ph.D. student, Susana Pascoal, working in

Fig. 4. The Left-Right (L-R) asymmetrical patterning and the synchronization of the segmentation clock. (A) Schematic representation of a normal embryo where the Left and the Right lateral plate mesoderm express a different set of genes represented by different colours. In this situation, a correct $L-R$ asymmetric positioning of the internal organs will be achieved. The Left and the Right presomitic mesoderm show perfectly synchronized cyclic expression patterns. This will be important for the L-R symmetry of somite formation. (B) Schematic representation of an embryo lacking terra where the Left and Right lateral plate mesoderm loose a differential L-R identity and at the level of the presomitic mesoderm, the cyclic expression pattern is desynchronised between the Left and the Right sides.
$L-R$ asymmetric organs and $L-R$ symmetric somites
$L-R$ randomized organs and $L-R$ asymmetric somites 


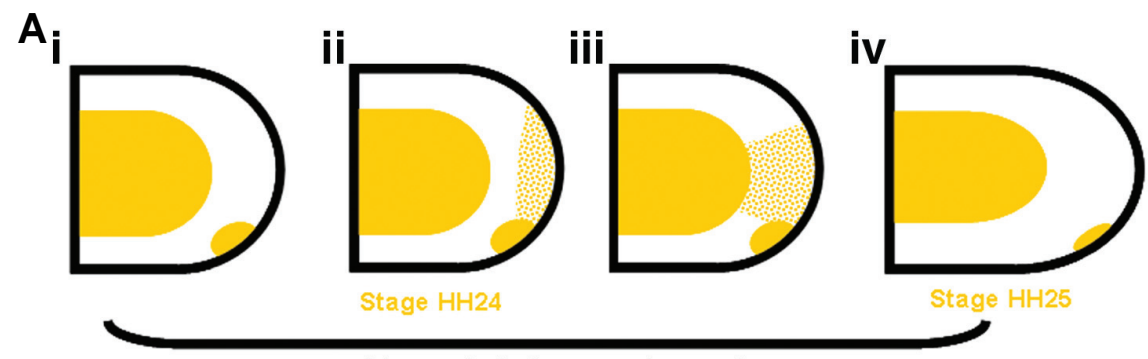

6 hours hairy 2 expression cycle

\section{B}
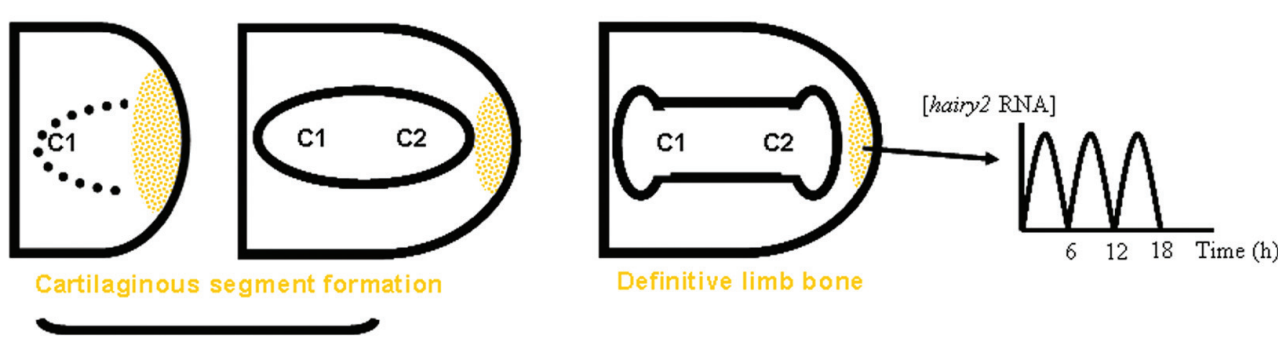

Limb skeletal element formation time - 12 hours

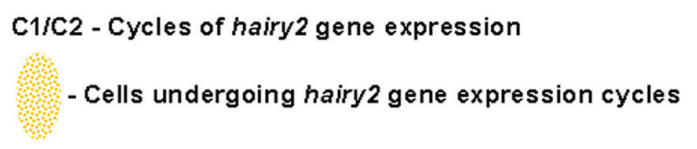

Palmeirim's group at the Instituto de Investigação em ciências da Vida e Saúde (ICVS), Braga. She showed that the somitogenesis clock component hairy2 presents cyclic gene expression in limb chondrogenic precursor cells, with a 6 hour periodicity. Susana also found that the time period of each hairy2 expression cycle in the limb bud correlates with the time required to form an autopod skeletal limb element, which she found to be 12 hours (Fig. 5). These observations led the authors to propose that each phalange is formed by two subsets of cells that leave the PZ during as hairy2 performs two cycles of expression (Fig. 5B, Pascoal et al., 2007; Pascoal and Palmeirim, 2007). More exciting is the fact that these results put forward the possibility that temporal control exerted by cyclic gene expression is not an exclusive property of PSM cells; instead it can be a more general mechanism providing cellular temporal information during vertebrate embryonic development.

\section{Final remarks}

The identification of the segmentation molecular clock brought new insights into how embryonic cells count time. Oscillatory gene expression has been reported in the laid-down of two major vertebrate segmented body structures: the vertebrae and the limb bone, evidencing the relevance of the molecular clock in these two processes. Correct embryonic development only occurs when the right cell is located at the right moment in the right place. This implies that embryonic cells must acquire temporal and positional information simultaneously along the three body axes. Could the molecular clock be a widespread mechanisms operating in the formation of a high variety of vertebrate embryonic processes such as lung, trachea, kidney, nervous system? Could this provide embryonic cells with temporal information which can
Fig. 5. A molecular clock is ticking during limb bud development. (A) Scheme of the different hairy2 gene expression patterns observed for the same stage of limb bud development (stage HH24). We can observe a negative expression pattern of hairy2 in (i), followed in (ii) by an intermediate expression pattern, and subsequently by a strong hairy2 expression pattern (iii). In (iv) we can observe that after 6 hours, the time required for one hairy2 expression cycle in limb bud development, the expression pattern of hairy2 is negative again and the limb reaches another stage of development (stage HH25). (B) Scheme of the correlation between the 6 hours periodicity of the hairy2 expression cycle in limb bud and the 12 hours necessary for the formation of one autopod limb skeletal element. We propose that limb chondrogenic precursor cells are continuously performing hairy2 expression cycles while in the limb distal mesenchyme since early stages of limb bud development. As the limb bud grows the cells leave the distal zone, stop cycling and differentiate (C1/C2). Every 12 hours, a limb autopod skeletal element is formed by two sets of cells (C1/C2) that have seen two different cycles of hairy2 expression.

be intimately related to positional information? How does the clock work, i.e., which is the mechanism that initiates and maintains this oscillatory gene transcriptional behaviour? What is the biological function of this molecular clock? Could the impairment of this mechanism be the basis of some genetic disorders? These are some questions that we would like to answer, whether in Portugal or anywhere else in the world!

\section{Acknowledgments}

We wish to thank to Leonor Saúde and Raquel Andrade for critical reading of the manuscript. Financial support was provided by FCT/ FEDER (POCTI/BCI/42040/2001) and by the EU/FP6-Network of EXCe/lence-Cells into Organs. S.P. (SFRH/BPD/26638/2006) was supported by FCT, Portugal.

\section{References}

ANDRADE, R.P., PASCOAL, S. and PALMEIRIM, I. (2005). Thinking clockwise. Brain Res. Rev. 49: 114-119.

ANDRADE, R.P., PALMEIRIM, I. and BAJANCA, F. (2007). Molecular clocks underlying vertebrate embryo segmentation: a 10-year-old hairy-go-round. Birth Defects Res C Embryo Today. 81: 65-83.

AULEHLA, A., WEHRLE, C., BRAND-SABERI, B., KEMLER, R., GOSSLER, A., KANZLER, B. and HERRMANN, B.G. (2003). Wnt3a plays a major role in the segmentation clock controlling somitogenesis. Dev. Cel/4: 395-406.

CATALA, M., TEILLET, M.A., DE ROBERTIS, E.M. and LE DOUARIN, M.L. (1996). A spinal cord fate map in the avian embryo: While regressing, Hensen's node lays down the notochord and floor plate thus joining the spinal cord lateral walls. Development 122: 2599-2610.

COOKE, J. and ZEEMAN, E.C. (1976). A clock and wavefront model for control of the number of repeated structures during animal morphogenesis. J. Theor. Biol. 58: 455-476.

DALE, J.K., MAROTO, M., DEQUEANT, M.L., MALAPERT, P., MCGREW, M. and POURQUIE, O. (2003). Periodic notch inhibition by lunatic fringe underlies the 
chick segmentation clock. Nature 421: 275-278.

DALE, J.K., MALAPERT, P., CHAL, J., VILHAIS-NETO, G., MAROTO, M., JOHNSON, T., JAYASINGHE, S., TRAINOR, P., HERRMANN, B. and POURQUIE, O. (2006). Oscillations of the snail genes in the presomitic mesoderm coordinate segmental patterning and morphogenesis in vertebrate somitogenesis. Dev. Cel/10: 355-366.

DEQUEANT ML, GLYNN, E., GAUDENZ K, WAHL M, CHEN J, MUSHEGIAN A, POURQUIE O. (2006). A complex oscillating network of signalling genes underlies the mouse segmentation clock. Science 314: 1595-1598.

DUDLEY, A.T., ROS, M.A. and TABIN, C.J. (2002). A re-examination of proximodistal patterning during vertebrate limb development. Nature 418: 539-544.

FISHER, D.A., KIVIMAE, S., HOSHINO, J., SURIBEN, R., MARTIN, P.M., BAXTER, N. and CHEYETTE, B.N. (2006). Three dact gene family members are expressed during embryonic development and in the adult brains of mice. Dev. Dyn. 235: 2620-2630.

FREITAS, C., RODRIGUES, S., CHARRIER, J.B., TEILLET, M.A. and PALMEIRIM, I. (2001). Evidence for medial/lateral specification and positional information within the presomitic mesoderm. Development 128: 5139-5147.

FREITAS, C., RODRIGUES, S., SAUDE, L. and PALMEIRIM, I. (2005). Running after the clock. Int. J. Dev. Biol. 49: 317-324.

HIRATA, H., YOSHIURA, S., OHTSUKA, T., BESSHO, Y., HARADA, T., YOSHIKAWA, K. and KAGEYAMA, R. (2002). Oscillatory expression of the bHLH factor hes 1 regulated by a negative feedback loop. Science 298: 840-843.

HIRATA, H., BESSHO, Y., KOKUBU, H., MASAMIZU, Y., YAMADA, S., LEWIS, J. and KAGEYAMA, R. (2004). Instability of hes7 protein is crucial for the somite segmentation clock. Nat. Genet. 36: 750-754.
ISHIKAWA, A., KITAJIMA, S., TAKAHASHI, Y., KOKUBO, H., KANNO, J., INOUE T. and SAGA, Y. (2004). Mouse nkd1, a Wnt antagonist, exhibits oscillatory gene expression in the PSM under the control of Notch signalling. Mech. Dev. 121: $1443-1453$

MONK, N.A. (2003). Oscillatory expression of hes1, p53, and NFkappaB driven by transcriptional time delays. Curr. Biol. 13: 1409-1413.

PALMEIRIM, I., HENRIQUE, D., ISH-HOROWICZ, D. and POURQUIE, O. (1997) Avian hairy gene expression identifies a molecular clock linked to vertebrate segmentation and somitogenesis. Cel/91: 639-648.

PASCOAL, S., CARVALHO, C.R., RODRIGUEZ-LEON, J., DELFINI, M.-C., DUPREZ, D., THORSTEINSDOTTIR, S. \& PALMEIRIM, I. (2007). A molecular clock operates during chick autopod proximal-distal outgrowth. J. Molec. Biol. 368: 303-309. (doi:10.1016/j.jmb.2007.01.089)

PASCOAL, S. and PALMEIRIM, I. (2007). Watch-ing out for chick limb development. Integr. Comp. Biol. 47: 382 - 389.

RIDA, P.C., LE MINH, N. and JIANG, Y.J. (2004). A notch feeling of somite segmentation and beyond. Dev. Biol. 265: 2-22.

SAUDE, L., LOURENCO, R., GONCALVES, A. and PALMEIRIM, I. (2005). Terra is a left-right asymmetry gene required for left-right synchronization of the segmentation clock. Nat. Cel/ Biol. 7: 918-20.

SUMMERBELL, D., LEWIS, J.H. and WOLPERT, L. (1973). Positional information in chick limb morphogenesis. Nature 244: 492-496.

SURIBEN, R., FISHER, D.A. and CHEYETTE, B.N. (2006). Dact1 presomitic mesoderm expression oscillates in phase with axin2 in the somitogenesis clock of mice. Dev. Dyn. 235: 3177-3183.

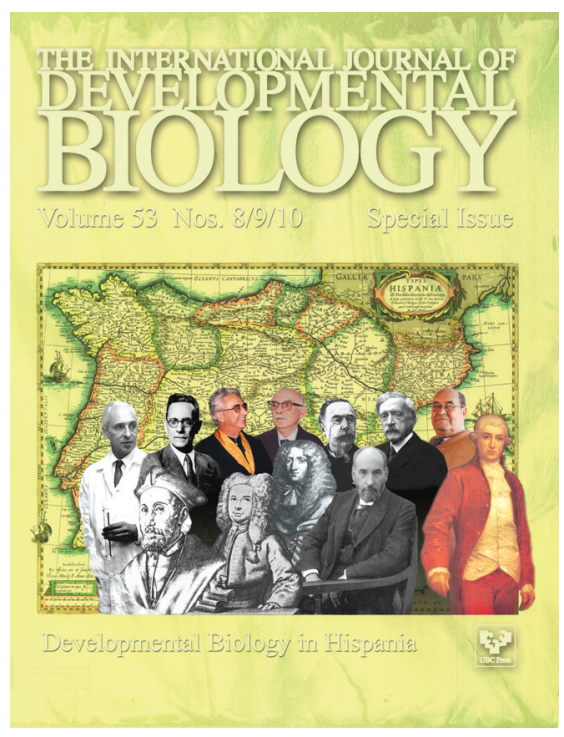




\section{Related, previously published Int. J. Dev. Biol. articles}

See our recent Special Issue Ear Development edited by Fernando Giraldez and Bernd Fritzsch at: http://www.ijdb.ehu.es/web/contents.php?vol=51\&issue=6-7

The road to the vertebral formula

Moisés Mallo, Tânia Vinagre and Marta Carapuço

Int. J. Dev. Biol. (2009) 53: 1469-1481

Embryonic heat shock reveals latent hsp90 translation in zebrafish (Danio rerio)

Michelle H. Connolly and Brian K. Hall

Int. J. Dev. Biol. (2008) 52: 71-79

A comparative analysis of Meox1 and Meox2 in the developing somites and limbs of the chick embryo Susan Reijntjes, Sigmar Stricker and Baljinder S. Mankoo

Int. J. Dev. Biol. (2007) 51: 753-759

Bowline, a novel protein localized to the presomitic mesoderm, interacts with Groucho/TLE in Xenopus Akiko Kondow, Keisuke Hitachi, Tempei Ikegame and Makoto Asashima

Int. J. Dev. Biol. (2006) 50: 473-479

Evolutionary embryology resurrected in Japan with a new molecular basis: Nori Satoh and the history of ascidian studies originating in Kyoto during the 20th century

Shigeru Kuratani, Hiroshi Wada, Rie Kusakabe And Kiyokazu Agata

Int. J. Dev. Biol. (2006) 50: 451-454

Circadian clock signaling in Arabidopsis thaliana: from gene expression to physiology and development

Paloma Más

Int. J. Dev. Biol. (2005) 49: 491-500

Running after the clock

Catarina Freitas, Sofia Rodrigues, Leonor Saúde and Isabel Palmeirim

Int. J. Dev. Biol. (2005) 49: 317-324

Synchronised cycling gene oscillations in presomitic mesoderm cells require cell-cell contact Miguel Maroto, J. Kim Dale, Mary-Lee Dequéant, Anne-Cécile Petit and Olivier Pourquié Int. J. Dev. Biol. (2005) 49: 309-315

PVF1/PVR signaling and apoptosis promotes the rotation and dorsal closure of the Drosophila male terminalia

Ana Macías, Nuria M. Romero, Francisco Martín, Leonardo Suárez, Alberto L. Rosa and Ginés Morata

Int. J. Dev. Biol. (2004) 48: 1087-1094

Vertebrate somitogenesis: a novel paradigm for animal segmentation?

Olivier Pourquié

Int. J. Dev. Biol. (2003) 47: 597-603

The circadian gene Clock is required for the correct early expression of the head specific gene Otx2.

Richard Morgan

Int. J. Dev. Biol. (2002) 46: 999-1004

Cyclic transcription of Hox genes suggests a link between patterning and the segmentation clock

József Zákány, Marie Kmita, José-Luis de la Pompa and Denis Duboule Int. J. Dev. Biol. (2001) 45: S23-S23

Microinjection of suc1 transcripts delays the cell cycle clock in Patella vulgata embryos.

P Colas, F Serras and A E Van Loon Int. J. Dev. Biol. (1993) 37: 589-594

5 yr ISI Impact Factor $(2008)=3.271$

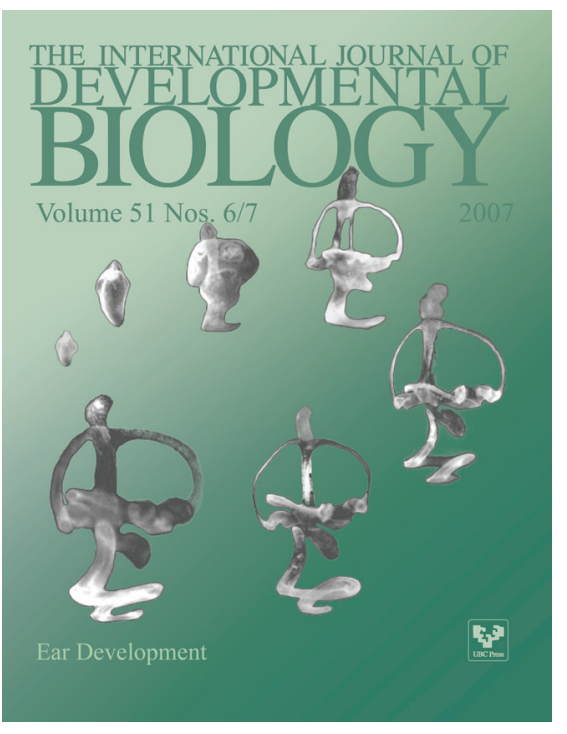

